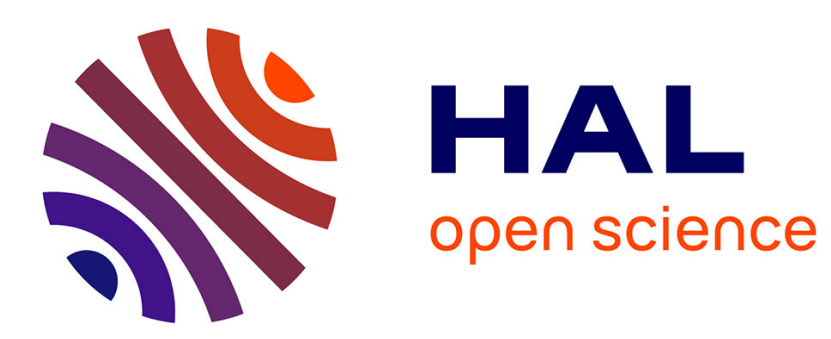

\title{
Conception and evaluation of a 3D musculoskeletal finite element foot model.
}

\author{
A Perrier, V Luboz, M Bucki, N Vuillerme, Yohan Payan
}

\section{To cite this version:}

A Perrier, V Luboz, M Bucki, N Vuillerme, Yohan Payan. Conception and evaluation of a 3D musculoskeletal finite element foot model.. Computer Methods in Biomechanics and Biomedical Engineering, 2015, 18 Suppl 1, pp.2024-2025. 10.1080/10255842.2015.1069606 . hal-01217790

\section{HAL Id: hal-01217790 \\ https://hal.science/hal-01217790}

Submitted on 20 Oct 2015

HAL is a multi-disciplinary open access archive for the deposit and dissemination of scientific research documents, whether they are published or not. The documents may come from teaching and research institutions in France or abroad, or from public or private research centers.
L'archive ouverte pluridisciplinaire $\mathbf{H A L}$, est destinée au dépôt et à la diffusion de documents scientifiques de niveau recherche, publiés ou non, émanant des établissements d'enseignement et de recherche français ou étrangers, des laboratoires publics ou privés. 


\title{
Conception and evaluation of a 3D musculoskeletal finite element foot model
}

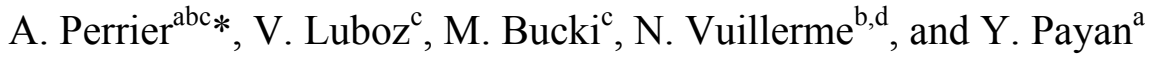 \\ a. Univ. Grenoble Alpes, CNRS, TIMC-IMAG, F-38000 Grenoble, France; ${ }^{b .}$ UJF-Grenoble1/AGIM; \\ ${ }^{c}$ TexiSense, Montceau-les-Mines, France, ${ }^{d .}$ Institut Universitaire de France, Paris, France
}

Keywords: Foot model; Finite Element; Musculoskeletal; Motion Analysis; Plantar Pressure.

\section{Introduction}

Modelling the foot accurately is essential in understanding its behaviour under healthy and pathological conditions. For example, it has helped analysing risks of injuries in diabetic foot (Chen et al. 2010). This work aims at developing and evaluating a patient-specific Finite Element (FE) model of the foot in the context of pressure ulcer prevention, orthopedic and motion analysis. Using the most recent functional knowledge about foot anatomy is necessary to simulate functions such as support, weight bearing, locomotion or foot surgery and its consequences.

\section{Methods}

\subsection{Modeling}

The model has been developed using the 3D biomechanical simulation platform ArtiSynth (artisynth.org). Starting from a CT and an MRI exam of a single patient, 30 bones have been modelled as articulated rigid-bodies connected with cables that simulate the 210 segmented ligaments in their actual positions and therefore define the articulations with contact. The Aponeurosis is modelled with five parallel multipoint ligaments connected by transversal ligaments. 15 extrinsic and intrinsic Hill's model muscles have been positioned according to their anatomical course and can be independently activated in order to allow a natural movement of the foot.

A FE mesh of the soft tissue was created by applying a new automatic FE mesh generator, TexiMesh (texisense.com), to the surfaces resulting from MRI and CT segmentation. The FE mesh has 142,060 elements (mainly hexahedrons) and 66,362 nodes. Three soft tissue layers with Neo Hookean materials (Young moduli, Poisson Ratio) were created to represent a $1 \mathrm{~mm}$ skin layer $(200 \mathrm{kPa}, 0.485)$, the fat $(30 \mathrm{kPa}, 0.49)$ and muscle $(60 \mathrm{kPa}, 0.495)$ tissues, Fig $2 \mathrm{~A}$. A fourth layer represents the heel anatomical soft structure (100kPa, 0.4998).

\subsection{Weight bearing evaluation}

The foot model was first evaluated for static weight bearing position. We compared (Fig 1) simulated plantar pressure (SPP) with the real plantar pressure
(RPP) collected in the same patient standing onto a Zebris FDM-SX platform. For this simulation, half of the patient's weight was applied onto the foot model while in contact with a horizontal finite element plate (Fig 1 B) having the same number of "sensors" as the Zebris platform (one element per sensor). In order to represent dynamic loading, the muscles first make a dorsiflexion before foot contact. We compare the mean pressure (MP) and peak pressure (PP) at platform surface after regionalization (Gefen et al. 2000) using a dedicated software, TexiLab (texisense.com). The real plantar pressures are the mean of four trials.

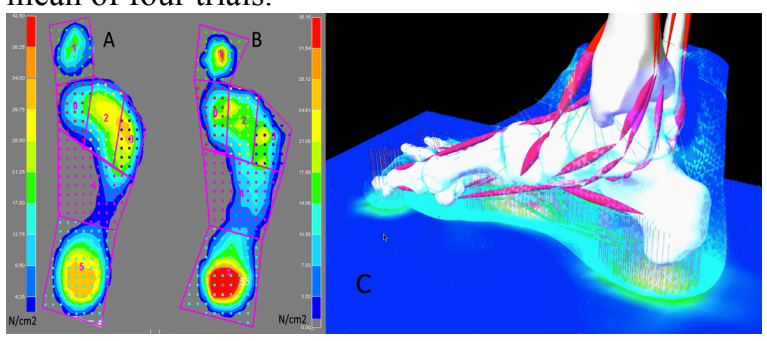

Fig1: A. Real PP, B. Simulated PP, C. Stress

visualization of the $\mathrm{FE}$ model in weight bearing position

\subsection{Dynamic evaluation}

This evaluation was made during an adduction / abduction movement: a 3D motion analysis of the patient's foot was performed using the Leardini's marker set (Leardini et al. 1999). A needle and surface EMG monitoring of the Tibialis Posterior, Tibialis Anterior, Triceps and Peroneus muscles were used as inputs for the simulation. Local referential and regression equations were created to have 3D point comparison between virtual markers from motion analysis and real anatomical markers from CT reconstruction, to assess our model's motions resulting from simulated muscle activations (Fig 2). For the simulated and real kinematics (five trials), we compared the 3D angle formed by the mass center of the tibia, the mass center of the talus and the center of the second metatarsal head, considered as an anatomical axis of the foot. Angle measurements were also performed in $2 \mathrm{D}$ after projecting the reference points on the three anatomical planes.

*Corresponding author. Email: antoine.perrier@imag.fr 
Movements were split into

- Dorsal/plantar flexion in the sagittal plane

- Pronation/supination in the frontal plane,

- Abduction/adduction in the horizontal plane.

These categories were made to facilitate a clinical interpretation of the results.

In this paper, only the Abduction (ABD) / Adduction (ADD) kinematics is studied.

\section{Results and discussion}

\subsection{Weight bearing simulation}

Table 1 compares the simulated and real peak and mean pressures under the second (region 2) and the fourth/fifth (region 3) metatarsal heads. The simulated pressures are close to the real ones considering pressure measurement and subject weight uncertainties. In the second metatarsal area (region 2), the differences between RPP and SPP are about 0.6 $\mathrm{N} / \mathrm{cm} 2$ for the MP and $1.6 \mathrm{~N} / \mathrm{cm} 2$ for the PP (Tab 1). In the fourth and fifth metatarsal area (region 3 ), the differences are $1.9 \mathrm{~N} / \mathrm{cm} 2$ for the MP and $0.9 \mathrm{~N} / \mathrm{cm} 2$ for the PP. We assumed that our precise results regarding the literature are due to the use of the vertical component of the simulated platform's Von Mises Stress (VMS) instead of foot's skin plantar VMS in others studies.

\begin{tabular}{|c|c|c|c|}
\cline { 2 - 4 } \multicolumn{1}{c|}{} & $\begin{array}{c}\text { Real } \\
\text { Pressure }\end{array}$ & $\begin{array}{c}\text { Simulated } \\
\text { Pressure }\end{array}$ & Difference \\
\cline { 2 - 4 } \multicolumn{1}{c|}{} & $\underline{\text { Region } 2}$ & $\underline{\text { Region } 2}$ & \multicolumn{1}{c|}{} \\
\hline Mean Pressure & $2.9 \mathrm{~N} / \mathrm{cm} 2$ & $2.3 \mathrm{~N} / \mathrm{cm} 2$ & $0.6 \mathrm{~N} / \mathrm{cm} 2$ \\
\hline Peak pressure & $14.1 \mathrm{~N} / \mathrm{cm} 2$ & $15.9 \mathrm{~N} / \mathrm{cm} 2$ & $1.6 \mathrm{~N} / \mathrm{cm} 2$ \\
\hline Mean Pressure & $\underline{\text { Region } 3}$ & $\underline{\text { Region } 3}$ & \multicolumn{1}{c|}{} \\
\hline Peak Pressure & $4.3 \mathrm{~N} / \mathrm{cm} 2$ & $2.4 \mathrm{~N} / \mathrm{cm} 2$ & $1.9 \mathrm{~N} / \mathrm{cm} 2$ \\
\hline & $16.6 \mathrm{~N} / \mathrm{cm} 2$ & $17.5 \mathrm{~N} / \mathrm{cm} 2$ & $0.9 \mathrm{~N} / \mathrm{cm} 2$ \\
\hline Real & Simulated & Difference \\
\hline Kingle 3D MAX & $146.7^{\circ}$ & $149.1^{\circ}$ & $\mathbf{1 . 6} \%$ \\
\hline Angle 3D MIN & $114.9^{\circ}$ & $110.6^{\circ}$ & $-3.9 \%$ \\
\hline Angle 2D ADD MAX & $148.8^{\circ}$ & $149.4^{\circ}$ & $\mathbf{0 . 4} \%$ \\
\hline Angle 2D ABD MAX & $115^{\circ}$ & $113^{\circ}$ & $\mathbf{- 1 . 8 \%}$ \\
\hline
\end{tabular}

Tab 1: Static and dynamic results

\subsection{Dynamic EMG simulation}

Table 1 provides simulated kinematics with muscle activation using real EMG input. The corresponding 3D angle between the tibia and second metatarsal bone is $1.6 \%$ greater than real anatomical measurements for the maximum 3D angle and 3.9\% smaller for the minimal 3D angle. More than $120^{\circ}$ could be considered has a complex motion with adduction and plantar flexion. Less than $120^{\circ}$ could be a synergic function of the dorsiflexion and the abduction. The projection angle, in the horizontal plane, is $0.4 \%$ greater in adduction and $1.8 \%$ smaller in abduction. These excellent results should be carefully analysed since the reference frame is fixed to the tibia during simulation, while it has a skin marker dependency for the real motion analysis. The

projected angles could thus be misestimated and the difference could be greater.

These results are preliminary and cannot be compared to other biomechanical finite element studies since it is, to our knowledge, the first time real EMG input was used for assessing foot motion during swing phase or unloading.

Our work was limited to only one case since we wanted to evaluate the model with real data. It is important to note that our group has already proposed a methodology to easily adapt this single model to other patients' anatomy. Other patient-specific simulations could thus be performed.

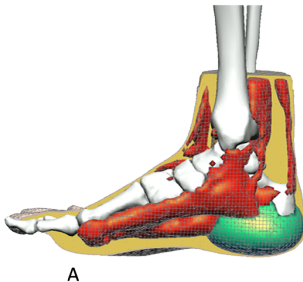

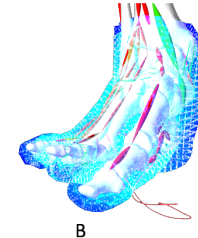

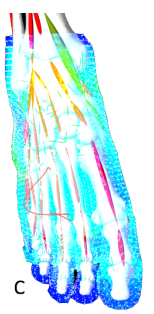

Fig 2: A. Finite Element model, B. Abduction kinematic, C. Adduction kinematic.

\section{Conclusions}

This paper has introduced a new musculoskeletal and finite element foot model providing realistic simulations in both static and dynamic frameworks. The ranges of motion in dynamic, and plantar pressure in loading condition, are anatomically and clinically realistic.

Other studies using this model will simulate ankle arthrodesis or foot orthotics. The model could also become relevant for the simulation of neuroorthopedic surgical interventions, orthotic devices analysis or educational purposes like functional anatomy

\section{Acknowledgements}

This work is partly funded by the French national project ANR -TecSan 2010-013 IDS

\section{References}

Gefen A, Megido-Ravid M, Itzchak Y, Arcan M. 2000 Biomechanical analysis of the threedimensional foot structure during gait: a basic tool for clinical applications. J Biomech Eng 122:630639

Leardini A, Benedetti MG, Catani F, Simoncini L, Giannini S.1999 An anatomically based protocol for the description of foot segment kinematics during gait. Clin Biomech 14(8): 528-36.

Chen WM, Lee T, Lee P, Lee SJ. 2010 Effects of internal stress concentrations in plantar soft-tissue. Med. Eng. \& Phys. 32 324-331. 